\title{
Management of the obese
}

\section{obstetric patient}

LP Gan', C Khaghani' 1 , A Radford², S Foster ${ }^{1}$

${ }^{1}$ Royal Hampshire County Hospital, ${ }^{2}$ Southampton General Hospital

\section{Background}

In the United Kingdom obesity is increasing. Over the last 20 years, numbers of obese pregnant women have doubled.

Complications from obesity during pregnancy have significant implications for the mother and newborn, and women who die during pregnancy are more likely to be obese. ${ }^{1}$

Accurate booking BMIs must be calculated, as self-reported weight is often underestimated, especially in obese women. The CMACE/RCOG joint guideline recommends that obese women be re-weighed in the third trimester to enable appropriate planning and management. ${ }^{1}$

\section{Methods}

We prospectively audited practice within Royal Hampshire County Hospital (RHCH) for calculating booking BMI's, weighing patients on admission and informing the anaesthetist about obese patients.

Patients admitted to labour ward were randomly selected between June and July 2015. Information was collected on their booking weight, booking BMI, admission weight and whether the duty anaesthetist had been informed following their admission.

\section{Results}

Data was obtained on 42 women in labour. All had a booking weight recorded and $39(93 \%)$ had their BMI calculated from this. $81 \%$ of booking weights were recorded in kilograms, however 19\% were recorded in imperial measurements.

$11(26 \%)$ women were obese (6 had a BMI $>30$ and 5 BMI $>40$ ). Of patients whose BMI was $>40$, the anaesthetist was informed following admission about $4(80 \%)$ of them.

Only 8 women were re-weighed following admission. Average weight gain was $10.5 \mathrm{~kg}$ (Range $2.7 \mathrm{~kg}$ - 23kg).
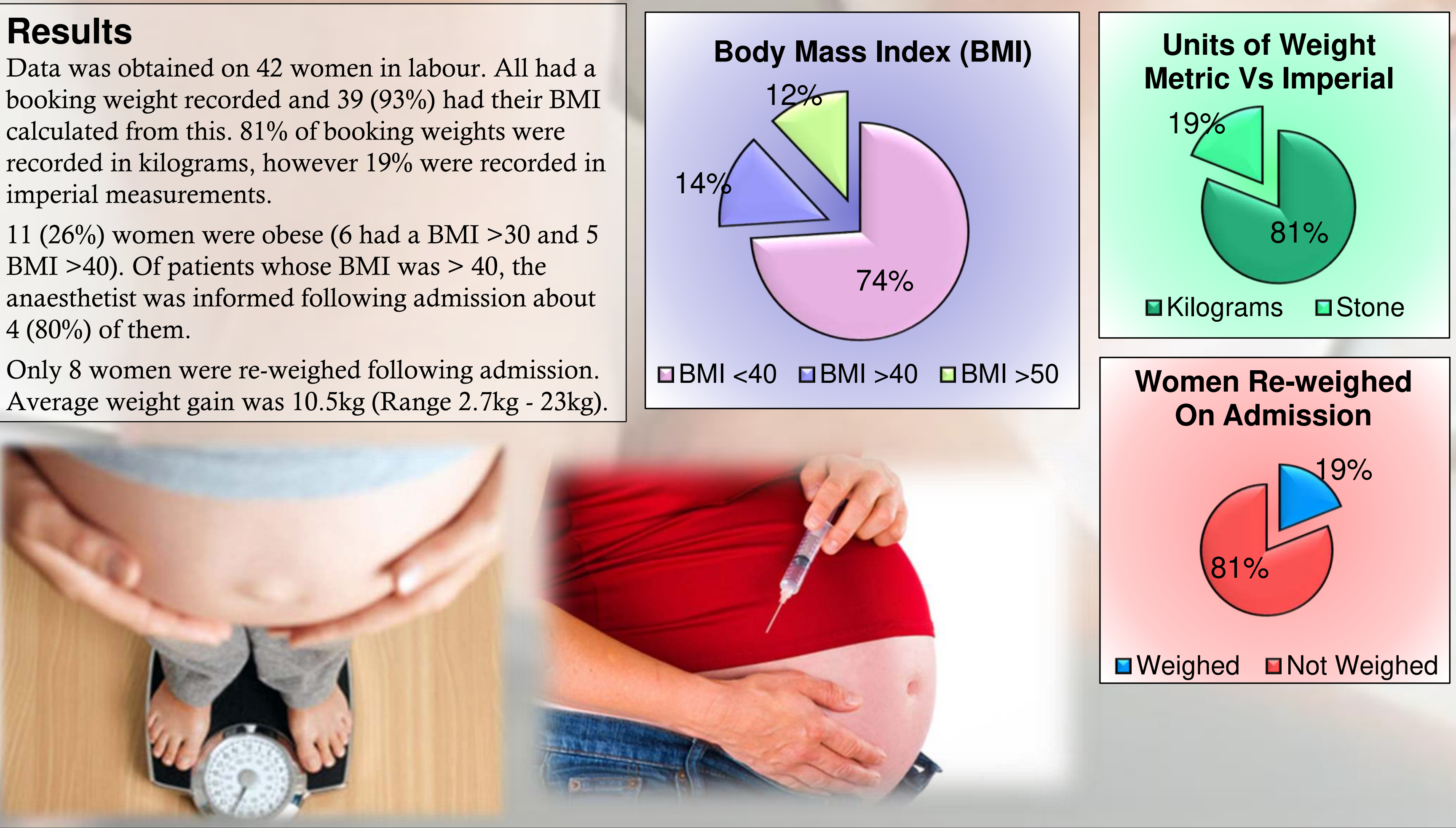

\section{Discussion}

A considerable number of booking weights were recorded in imperial units, requiring conversion to metric units for drug dosing, introducing more room for error. It also indicated that weights were possibly estimated by women themselves. Inaccurate weights may impact on dosing of enoxaparin for VTE prophylaxis and drugs for anaesthesia. Obese women with BMI > 40 may not be identified if booking weights are underestimated.

Only 8 women were weighed on admission. The largest increase in weight was $23 \mathrm{~kg}$. Significant weight gain during pregnancy may be missed and this could affect obstetric and anaesthetic management.

Evidence is lacking on which weight should be used for drug dosing, which could lead to significant under-dosing.

\section{Conclusion}

We recommend accurate height and weight is taken during booking appointments using appropriate (metric) equipment to calculate an accurate BMI. If BMI is over 30, her weight should be repeated following admission. The duty anaesthetist should be informed when a parturient with a BMI $>40$ is admitted. Consensus opinion on which weight to use for drug dosing is needed.

\section{References}

